\title{
An overview of aesthetic surgery of the breast
}

\author{
Umar Daraz Khan \\ Aesthetic Plastic Surgeon, Reshape House, West Mallling, ME19 6QR, UK. \\ Address for correspondence: Mr. Umar Daraz Khan, Aesthetic Plastic Surgeon, Reshape House, 2-4 High Street, West Mallling, ME19 6QR, UK. \\ E-mail: Mrumarkhan@aol.com
}

Aesthetic surgery for the breast is one of the common procedure performed by an aesthetic plastic surgeon today. The surgery is frequently performed for aesthetic as well reconstructive reasons. Breast itself is a uniquely important part of the female body and as such embodies in itself anatomical, physiological and aesthetic role. A proportionately developed breast is an important feminine feature, a sign for fertility and sexuality. It is not surprising that breasts are extremely important for women's selfconfidence especially when their role in society has expanded immensely.

Aesthetic surgery for breast is not new and has been practiced for many years for reduction, enhancement and mastopexy. However, the introduction of implants by Cronin and Gerow in 1962, has given a new dimension to breast remodelling. Surgery for breast reduction, breast reconstruction, mastopexy and augmentation comprises the most common procedure performed today. Use of implant alone has increased exponentially in the second half of last century and breast augmentation for reshaping and remodelling alone has overtaken almost any other aesthetic procedure, including breast reduction, mastopexy and reconstruction. The safety of implants and choice of shape and volume has given a range of choices and predictability to patients for aesthetic and reconstructive reasons.

A variety of procedures are available for patients with inadequate breast development, breast hypertrophy, developmentally ptotic breasts, involution secondary to pregnancy, weight or age related changes or to correct breast asymmetry. Breast implants either alone or in combination has given versatility and predictability for a desirable breast shape, volume or positioning. Small volumetric enhancement or asymmetries can be corrected

\begin{tabular}{|l|l|}
\hline \multicolumn{2}{|c|}{ Access this article online } \\
\hline Quick Response Code: & Website: \\
\hline & http://par.oaepublish.com/ \\
\cline { 2 - 3 } & \\
& \\
\end{tabular}

using autologous fat grafting in selected cases. Advancement in imaging techniques has enable to provide better breast screening that can delineate suspicious breast lesions following use of breast implants or autologous fat grafting.

Augmentation mammoplasty alone using breast implants is the leading aesthetic procedure for breast remodelling. Safety of the implants paired with a high patient satisfaction has made this procedure very suitable and desirable in selected cases. Autologous fat grafting is becoming an increasingly used alternative for augmentation mammoplasty. The choice is especially useful for correction of breast asymmetries and for moderate size bilateral enhancement in selected cases. The use of autologous fat grafting is increasingly used for revision surgeries in aesthetic and reconstructive breast procedures alike.

Simultaneous mastopexy with augmentation is becoming more popular and staged procedure is broadly limited to selected cases. An abundant literature is available citing the efficacy of the combined procedure with acceptable revision rate. A variety of shape, size, profiles and filler materials are available with a choice of formed or expander prosthesis. Combination of desired implant along with choices for implant pockets, flap orientation for nipple elevation and selection of skin marking for envelope reduction has enabled surgeons to tailor make each surgery for each individual.

The use of synthetic mesh has shown more promising results in breast reconstructive, primary or secondary augmentation mammoplasty and augmentation mastopexy. Breast implant capsule flaps are more frequently used and various techniques have been described for its use in primary

This is an open access article distributed under the terms of the Creative Commons Attribution-NonCommercial-ShareAlike 3.0 License, which allows others to remix, tweak and build upon the work non-commercially, as long as the author is credited and the new creations are licensed under the identical terms.

For reprints contact: service@oaepublish.com

How to cite this article: Khan UD. An overview of the aesthetic surgery of the breast. Plast Aesthet Res 2016;3:1-2.

Received: 30-10-2015; Accepted: 05-11-2015 
and secondary cosmetic and reconstructive surgeries with very good results.

We have a range of breast reconstruction procedures at our disposal today. Breast reconstruction can be achieved using autologous breast tissue as pedicle flaps with or without implants or free tissue transfers with a variety of options. The most popular being perforators based free tissue transfers. Skin sparing mastectomy can also be combined with acellular dermal matrix that has given a new dimension and scope to the oncological breast reconstruction.

As the Editor of Special Issue on Aesthetic Surgery of Breast, I would also like to thank the editorial team of Plastic and Aesthetic Research for the invitation and for their consistent support. Also I would like to thank all the contributors who were able to share their experience and work with us in this special issue.

Last but not the least, I am very thankful to my dear friend and mentor, Dr. Thomas Biggs, who has supported, encouraged and guided me through my early formative days of article writings, presentations and teaching. He has been a source of inspiration and strength.

\section{Financial support and sponsorship} Nil.

\section{Conflicts of interest}

There are no conflicts of interest. 